\title{
Um caminho para atender às diferenças na escola
}

Letícia Portieri Monteiro

Pontifícia Universidade Católica

Kátia Stocco Smole

Universidade de Franca

\section{Resumo}

Em 1999, o Conselho de Educação Judaica do Rio de Janeiro implantou o Programa de Inovação Educativa (PIE) nas Escolas Israelitas do Rio de Janeiro para atender às novas tendências da educação brasileira. 0 presente trabalho tem como objetivo analisar as modificações ocorridas no ambiente escolar a partir da implantação e implementação do PIE em uma escola judaica do Rio de Janeiro. Esse programa apresenta como ideia central trabalhar os conceitos de aprendizagem ativa e de inteligências múltiplas na concepção de Piaget, Dewey e Gardner. Para analisarmos o PIE, utilizamos uma abordagem de natureza qualitativa com os participantes da pesquisa por meio de entrevistas semiestruturadas e observação das salas de aula do $1^{\circ}$ ao $5^{\circ}$ ano do ensino fundamental. Baseando-se no referencial teórico, foi feita a análise dos dados. Os resultados desse estudo indicaram que, a partir do programa, os profissionais envolvidos ficaram mais motivados a buscar informações e a renovar os seus conhecimentos para atenderem às diferenças entre os alunos, utilizando estratégias diversificadas, o que possibilita um trabalho mais dinâmico que facilita o desenvolvimento da autonomia nos estudantes. Como dificuldades relatadas para o desenvolvimento do PIE, foram citadas a grade de horários que precisa ser revista e o fato de as professoras terem que cumprir um currículo extenso. A escola ainda está em processo de adaptação a esse programa inovador, por isso é muito importante que os profissionais envolvidos constantemente reavaliem o desenvolvimento do programa, buscando modificações ou alternativas à medida que encontram dificuldades.

\section{Palavras-chave}

Inteligência múltiplas - Aprendizagem ativa - Metodologia de ensino - Currículo. 


\section{A pathway to attend to differences at school}

Letícia Portieri Monteiro

Pontifícia Universidade Católica

Kátia Stocco Smole

Universidade de Franca

\section{Contact:}

Kátia Stocco Smole

Rua Andaquara, 164

04673-120 - São Paulo - SP

E-mail: katia@mathema.com.br

\begin{abstract}
In 1999 the Rio de Janeiro Council for Jewish Education set in motion the Innovative Education Program (PIE) at the Israeli Schools of Rio de Janeiro with the purpose of following the recent trends of Brazilian education. The present work has as its objective to analyze the changes occurred in the school atmosphere since the onset and implementation of the program at a Jewish school in Rio. The program's central idea is to work with the concepts of active learning and multiple intelligences as proposed by Piaget, Dewey, and Gardner. To analyze the PIE we used a qualitative approach with the participants of the study through semi-structured interviews and observations in classrooms of the 1st to 5th years of fundamental education. The analysis of the data was based on the theoretical framework. The results indicate that, after the implementation of the program, the professionals involved gained in motivation to search for information and refresh their knowledge in order to attend to the differences between the pupils, making use of diversified strategies and thus encouraging a more dynamic work that facilitates the development of students' autonomy. In terms of difficulties faced in the development of the program, there was mention to the need to revise timetables, and to the fact that teachers now have to go through more extensive curricula. The school is still in the process of adapting to this innovative program, and therefore it is very important that the professionals involved constantly reevaluate the development of the program, trying to identify modifications and alternatives as difficulties arise.
\end{abstract}

\section{Keywords}

Multiple intelligences - Active learning - Teaching methodology Curriculum. 
Na maioria dos países, a educação é hoje uma prioridade nacional que, de acordo com suas características históricas, promovem reformas em seus sistemas educacionais com a finalidade de torná-los mais eficientes e equitativos para o preparo de uma nova cidadania, na qual os indivíduos possam ser capazes de enfrentar a revolução tecnológica que está ocorrendo no processo produtivo e seus desdobramentos políticos, sociais e éticos (Mello, 1998).

Nos últimos anos, cresceu a tendência de introduzir mudanças e inovações na sala de aula e na estrutura educativa em geral. As novidades se expressam em diferentes campos: desde a redefinição dos objetivos da educação e a fixação dos conteúdos, até uma modelagem distinta do perfil dos professores e da organização da sala de aula.

A pesquisa em estabelecimentos escolares vem se ampliando e motivando grande interesse e preocupação, aparecendo de forma mais intensa, há cerca de 30 anos, tanto nos Estados Unidos como na França e no Reino Unido. Na corrente que fez evoluir os estudos de sociologia da educação no âmbito do sistema educacional para unidades menores, parece que o estabelecimento escolar vem sentido dificuldades em conquistar seu lugar entre os dois objetos mais clássicos: a sala de aula e a relação entre a escola e a comunidade. Em uma cultura em que são privilegiados o domínio sobre a natureza e os valores da individualidade, a incerteza sobre o futuro faz com que o "sucesso" se constitua uma preocupação primordial (Forquin, 1995).

Os sistemas educacionais no mundo atual têm como meta principal contribuir para que os estudantes possam ser cidadãos ativos, solidários, críticos e democratas. 0 ensino e a aprendizagem que ocorrem nas salas de aula representam uma das maneiras de construir significados, reforçar e formar interesses sociais, formas de poder, de experiência, sempre com um significado cultural e político.

Num trabalho que visa formar esse tipo de cidadão, é imprescindível que sejam levados em consideração o conteúdo cultural, bem como as estratégias de ensino, aprendizagem e avaliações necessárias para realizar tal missão.

Nesse sentido, a educação em lsrael é um legado precioso. Quando o Estado de lsrael foi fundado (1948), um completo e funcional sistema de educação já existia, desenvolvido e mantido pela comunidade judia local e tendo o hebraico, que vinha sendo revivido pelo uso diário desde o final do século XIX, como idioma principal. Mesmo assim, logo após o estabelecimento do Estado, o sistema educacional enfrentou o enorme desafio de integrar um grande número de crianças de mais de 70 paises, algumas vindas com os pais e outras, sozinhas. Novos métodos de ensino tiveram que ser desenvolvidos para ajudar a absorver jovens vindos de diferentes culturas dentro de um mesmo ambiente escolar (Sechter, 2001).

\section{- problema}

A área de educação em lsrael teve que buscar modelos alternativos tal a diversidade de culturas presentes em sua população constituída por indivíduos oriundos de várias procedências. Nesse sentido, foram desenvolvidos estudos para que esses programas lograssem êxito, sem ameaçar a estrutura básica, os costumes e a tradição histórica daquele povo.

Dentre os métodos que surgiram, encontra-se o Oraá Mutemet, traduzido como Programa de Inovação Educativa (PIE), que está sendo aplicado naquela região e que leva em conta a heterogeneidade da clientela a ser alcançada por ele.

0 Estado de lsrael se propôs a construir um sistema educacional que influísse sobre o caráter da sociedade e sobre os produtos da educação. Por esse motivo e pela origem diversificada da população, desde o início, a política nacional tem se baseado no princípio da heterogeneidade das turmas, tanto nas escolas de ensino fundamental quanto nas de ensino médio. Essa política foi concebida a partir da necessidade de melhorar os resultados alcançados pelos alunos como um 
todo e de cultivar processos de integração social. Dentro desse conceito, surgiram alguns programas educacionais que até hoje estão vigorando em lsrael. No presente trabalho, será feita uma análise de um desses programas, o PIE, que trabalha contemplando o ensino diversificado.

No modelo brasileiro, o problema concentra-se no desafio de testar um programa que vem dando certo em lsrael, ressalvando-se que as razões na nossa realidade apoiam-se nas múltiplas habilidades a serem desenvolvidas nos alunos do ensino fundamental (classe de alfabetização à $5^{\mathrm{a}}$ série), habilidades essas fundamentais para a progressão destes, considerando-se as diferenças individuais tão presentes nas salas de aula.

\section{Educação para diversidade}

A suposição básica da abordagem diversificada, considerando-se a existência de diferenças entre os alunos, leva à concepção socializante do ensino, que visa manter na classe heterogênea os mais diversos processos educacionais. Essa classe é concebida como sendo um contexto social e organizacional, que possibilita aos alunos melhoria nos resultados do estudo e amplo contato social. 0 conceito da classe heterogênea assinala não somente a diferença de ritmos de aprendizagem, mas um conjunto de indivíduos diferentes sob vários aspectos: origem, características pessoais, estilo na aprendizagem, tendências, necessidades, vontades, capacidades, dificuldades e outras variáveis.

A educação para a diversidade sugere reconhecer a heterogeneidade existente em cada turma, em todas as suas dimensões, como o ponto de partida para o planejamento e a organização do ensino e da aprendizagem, e atuar na criação de um ambiente que favoreça possibilidades de estudo e desenvolvimento pessoal e social aos estudantes, levando-se em consideração suas diferenças (Glubman; Yram, 1996).

A sociedade moderna está sofrendo mudanças rápidas e frequentes em consequência de desdobramentos ocorridos na economia e na tecnologia. A escola, por ocupar um lugar cen- tral na sociedade, torna-se uma instituição onde são depositadas as expectativas para atender a essas mudanças.

Dentro dessa nova concepção, o Conselho de Educação Judaica do Rio de Janeiro implantou, em 1999, o PIE nas Escolas lsraelitas desse município. Na América Latina, mais precisamente em Buenos Aires, esse programa de modernização das escolas judaicas completa seu oitavo ano de funcionamento ${ }^{1}$, tendo como principal objetivo colocar essas escolas prontas para preparar os cidadãos do século XXI, preservando seus valores culturais e morais. A formação de um cidadão crítico exige sua inserção numa sociedade em que o conhecimento científico e tecnológico é cada vez mais valorizado.

Esse programa vem ao encontro da reforma de ensino que está se processando no Brasil, onde a inovação maior da Lei de Diretrizes e Bases é preparar cidadãos, desenvolver competências e habilidades, onde a escola deve diversificar os métodos, investindo de significado os conteúdos, procurando ensinar a aprender e respeitando as diferenças individuais. Um dos princípios que também aparecem na Lei e que inova radicalmente a história da educação formal está expresso no artigo $1^{\circ}$ : "a educação deverá vincular-se ao mundo do trabalho e à prática social" e vem a corroborar a importância da implementação do PIE.

\section{A importância do PIE para as escolas judaicas no Brasil}

Segundo a Lei das Diretrizes e Bases da Educação Nacional (Lei n. 9.394), Artigo 10:

A educação abrange os processos formativos que se desenvolvem na vida familiar, na convivência humana, no trabalho, nas instituições de ensino e pesquisa, nos movimentos sociais e organizações da sociedade civil e nas manifestações culturais. (Brasil, 1996, p. 1)

1. Em 2003 , ano de conclusão desse trabalho, o programa nas escolas judaicas da Argentina que 0 adotaram já tinha oito anos. 
Em geral, costuma-se opor "educação como formação" e "educação como informação", oposição que reaparece quando se distinguem aprendizagem e treinamento, conscientização e pragmatismo, espírito crítico e alienação. Aqueles que privilegiam o polo formação/aprendizagem/ conscientização têm a esperança de que a educação possa ser um instrumento de conhecimento e de transformação do real graças à sua compreensão crítica.

Partindo desse princípio e em comunhão com as tendências atuais, o PIE tem a proposta de fazer mudanças na escola, entendendo-a como uma organização e uma totalidade. Essas mudanças devem ocorrer nos campos pedagógico, metodológico, social e tecnológico; no campo da organização e das relações entre as pessoas; e na maneira de planejar e de tomar decisões.

Os princípios do programa são construtivistas e, também, humanistas já que privilegiam a transmissão de valores. São democráticos e funcionam em escolas democráticas que aceitam trabalhar dessa forma. Trabalha-se com a ideia de diversidade de inteligência, aprendizagem, interesse, ritmo, conhecimentos anteriores, modalidades de comunicação e de organização das tarefas. Cada uma dessas características deve ser identificada pelo professor, em si mesmo e no aluno, para que ele possa levar a criança a reconhecer sua própria diversidade e, assim, possa construir uma proposta de trabalho que atenda a estas.

Em sua maioria, os professores atuais são fruto de um modelo de formação profissional que exigia apenas que se prestasse atenção à formulação de objetivos e metodologias, não considerando como sua incumbência a seleção explícita dos conteúdos culturais.

De acordo com os documentos analisados, nesse programa, o papel do professor muda muito. 0 professor deixa de ser o centro da aula, deixa de ser a única fonte de informação para as crianças e se converte em alguém que acompanha processos de busca e escolha de informação. Ele provê a criança de recursos para se organizar, sendo aquele que transmite conhecimentos, mas, acima de tudo, ajuda o aluno a construir sua formação. É um orientador da aprendizagem, alguém que deixa de ter como atividade principal a aula expositiva e assume a função de tutor.

A educação baseada na cópia ou na mera transmissão de conhecimento perde o sentido e passa a ter como estratégia primordial do desenvolvimento a construção do saber, por meio da pesquisa, de elaboração própria e de atualização constante.

Dentro do atual ritmo das inovações científicas e tecnológicas, a capacidade de atualização dos profissionais é decisiva no mundo todo. Levando-se esses aspectos em consideração para a implantação do programa nas escolas, foi importante promover a formação dos professores que atuam no PIE. Durante esse processo, muitos profissionais participaram de um curso em lsrael onde conheceram escolas que adotam o programa. No Brasil, discutiram e estudaram o currículo e a metodologia a ser adotada. A formação continuada ainda acontece sob a orientação de especialistas no programa que vêm ao Rio de Janeiro e mediante reuniões, na própria escola, com a direção, coordenação e corpo docente, nas quais há troca de experiências.

$\mathrm{Na}$ instituição educacional em estudo, faz parte do currículo a cultura judaica. Do ponto de vista de Santomé (1998), um currículo democrático, que respeite a diversidade política, cultural e linguística, tem que oferecer a possibilidade de que todos os estudantes compreendam a história, a tradição e os costumes de sua própria comunidade. Isso implica em conhecer também a dos demais povos no marco de uma filosofia de respeito, colaboração e solidariedade.

Nesse trabalho, quando mencionarmos o termo currículo, será no sentido trazido por Gimeno Sacristán (2000), qual seja: o de um conjunto de conhecimentos e experiências de aprendizagem oferecido aos estudantes que inclui não apenas a lista das disciplinas escolares que devem ser levadas até os alunos, mas também a forma de organização das turmas, a organização e gestão dos tempos, a escolha 
dos materiais e recursos para o processo de ensino e aprendizagem, as formas de controle e acompanhamento dos alunos, os valores preservados e vividos no cotidiano escolar, enfim, todo o modo de vida da escola.

\section{Inovações educacionais}

$\mathrm{Na}$ educação escolar, a história das inovações sempre aparece vinculada às questões ideológicas, sociais e econômicas. Uma inovação depende da conjuntura em que surge, de quem são seus promotores, da incidência e extensão que adquire. Hernández (2000) afirma que as inovações que tiveram maior incidência foram as que deram uma resposta alternativa às necessidades da escola ou da sociedade, por isso permaneceram na cultura da escola e favoreceram a qualidade do ensino e os diferentes sistemas educativos.

Na metade dos anos 1960, falar de inovações já fazia parte do discurso pedagógico e da cultura escolar. Esse período teve destaque nos Estados Unidos pela proliferação de inovações na educação e isso era uma tentativa de sanar os problemas sociais que estavam surgindo.

As inovações costumam ser produzidas por uma pressão externa (reforma educativa), pela vontade ou pelo desejo de mudança de um grupo ou de uma instituição. Foi o caso, por exemplo, dos Projetos de trabalho que surgiram em 1983, na Espanha, a partir da necessidade que professores do ensino fundamental sentiram em se aprofundar na teoria e na prática da globalização.

\section{Uma proposta inovadora}

Dentro dessa nova tendência, o PIE é considerado um projeto inovador porque se opõe ao método tradicional, ou seja, em vez de estar centrado no educador e no conhecimento, centra-se no educando e na vida. Os métodos convencionais não são apenas substituídos por outros. 0 que se repensa é a finalidade da educação, colocando-a a serviço da sociedade.
De acordo com a cultura de um estabelecimento escolar, um projeto de inovação será acolhido com hostilidade ou simpatia, desconfiança ou abertura. A cultura é representada pela forma como as pessoas, envolvidas nesse projeto, apropriam-se da informação que vem de fora e a assimilam; de como interpretam o que acontece na vida escolar; as intervenções dos pais, dos diretores; os dados da pesquisa; bem como qualquer ideia ou sugestão posta em circulação dentro da escola.

Segundo Thurler (2001), cada estabelecimento escolar reage de maneira diferente às ideias inovadoras e às reformas do sistema educativo de acordo com suas prioridades e sua definição de "boa escola". Os projetos de inovações obrigam os professores a questionarem as suas práticas, podendo provocar desestabilização que terá consequências diferentes, conforme as ideias inovadoras estejam inseridas na cultura estabelecida. De acordo com esse contexto, os professores estarão mais ou menos inclinados a se submeterem à autoridade.

De uma forma geral, os pesquisadores quando estudam inovações educativas, preocupam-se como estas são planejadas, realizadas e se houve, realmente, um processo de mudança. Toda ideia inovadora será justificada somente se contribuir para melhor alcançar as finalidades estabelecidas e garantir a eficiência no sistema educativo.

\section{Programa de inovação educativa}

\section{Concepção}

Quando chegou ao Brasil, o PIE recebia o nome de Oraá Mutemet que significa "Educação para Diversidade”, que é uma concepção educacional que reconhece a existência da diferença entre os estudantes e acredita que a função da escola é atender a essa diferença por meio do ambiente educativo adaptado às necessidades dos estudantes e aos objetivos do programa de estudo. Essa concepção educaci- 
onal afirma que é preciso colocar o aluno no centro do processo educativo, possibilitando que tenha o ritmo de estudo e o desenvolvimento adequados a si mesmo, oferecendo-lhe objetivos pedagógicos, culturais e pessoais condizentes com a sua possibilidade, tendências e necessidades, mediante uma participação ativa no processo e garantindo o seu progresso como indivíduo e como membro do grupo.

As raízes ideológicas do PIE podem ser encontradas na tradição judaica e em outras tradições antigas que tratam da posição do estudante e do professor. A ideia "Ensina o jovem de acordo com a sua natureza" faz parte do pensamento da filosofia educacional, da psicologia cognitiva e da psicologia humanista.

0 princípio orientador da educação para a diversidade é o de que na escola deve-se alcançar uma adequação entre o estudante individual, como parte do grupo, e o ambiente pedagógico, a fim de que lhe seja possível progredir e desenvolver o seu potencial.

A ideia central que orientou a concepção desse ensino foi o reconhecimento de que a função da escola e sua obrigação é criar um ambiente escolar que ofereça a cada aluno oportunidades educacionais para o sucesso e o crescimento, tanto no âmbito acadêmico quanto no social e pessoal.

\section{Mudanças}

Para atender aos objetivos do PIE, foram criadas estratégias de ensino e aprendizagem diversificadas e flexíveis que incluem a organização de um ambiente pedagógico rico que favoreça processos de ensino e aprendizagem variados, por meio do cultivo de uma nova cultura escolar, pedagógica e social. Esse ambiente pedagógico promove a flexibilidade de um programa de estudo que contém a diferenciação entre objetivos comuns para a totalidade dos estudantes e objetivos pessoais adequados a cada um; o progresso dos processos de ensino e aprendizagem pessoais e coletivos deve se ajustar à possibilidade, às tendências e às pre- ferências dos alunos; a utilização de uma larga variedade de técnicas, métodos e recursos; a flexibilização do tempo de estudo e âmbitos de aprendizagem, bem como o desenvolvimento de critérios e instrumentos de avaliação referentes ao progresso pessoal do aluno e a sua colaboração nos diferentes processos.

As estratégias de ensino e aprendizagem diversificadas utilizadas no PIE, também chamadas de trabalho diversificado, podem se apresentar por intermédio de atividades individuais, em grupo ou considerando-se toda a turma. Algumas vezes, o direcionamento às atividades é dado pelo professor; outras vezes, o aluno escolhe quais atividades quer realizar. Esses trabalhos podem acontecer dentro da própria sala de aula ou em outros espaços da escola, tais como: biblioteca, laboratório de informática ou laboratório de ciências.

0 trabalho diversificado permite ao professor acompanhar os alunos de acordo com seus ritmos de aprendizagem, dando-lhes um atendimento mais individualizado e sugerindo outras possibilidades tanto para aqueles que aprendem mais rapidamente, quanto para aqueles que levam mais tempo para aprender. Dessa forma, são oferecidas possibilidades de tempos diferentes para a aprendizagem.

Essas mudanças exigiram outras a elas associadas. A avaliação, por exemplo, deve ser realizada em diferentes etapas: como diagnóstico antes do estudo; como acompanhamento durante a aprendizagem; e como avaliação abrangente após um período em que o professor considera que a aprendizagem já ocorreu. Tanto o professor quanto o aluno participam desse processo, já que esse último pode acompanhar suas etapas de desenvolvimento mediante as fichas de observação e dos questionários de autoavaliação. Os instrumentos de avaliação são muito variados, tais como: atividades realizadas em sala, observação, conversas, jogos, portfólios, provas e outros.

A avaliação, assim como o planejamento das atividades, deve ser feita levando-se em consideração o nível de aprendizagem e o ritmo pessoal do aluno, os objetivos básicos do 
programa de ensino e os resultados normativos a serem alcançados. 0 ensino diversificado confere grande importância à avaliação do aluno em relação à sua capacidade pessoal e ao seu ritmo de aprendizagem. Isso possibilita o conhecimento do domínio alcançado pelo estudante no conteúdo estudado e a adaptação do ensino e da aprendizagem às suas necessidades.

É exigido do professor que integre setores do saber, do conhecimento referente ao aluno e aos processos de estudo, meios, métodos e recursos de ensino. As inovações sugeridas pela educação para diversidade exigem mudanças qualitativas que incluem posturas, aptidões e variedade de meios pedagógicos e didáticos por parte dos professores.

Algumas mudanças foram necessárias para a implantação do PIE nas escolas judaicas do RJ, tais como: reformar as salas de aula, criando um ambiente propício às atividades exigidas pelo programa; formar os professores - sendo que muitos foram para lsrael conhecer as escolas que adotam o programa e fazer um curso de atualização, continuando a serem estimulados pela presença de consultores que vêm ao Rio de Janeiro oferecer suporte -; e estender o horário de permanência dos alunos nas escolas, que passou a ser integral.

Para a realização de programas inovadores, precisa-se contar com profissionais que enfrentem os desafios da inovação, com um perfil definido por quatro referenciais, representados por autoconfiança, independência, espírito de pesquisa e visão cosmopolita (Moulin, 1988).

Para esse alcance, torna-se necessário que a formação de professores no âmbito geral e especificamente para a atuação no PIE esteja direcionada ao desenvolvimento desse perfil, o que nem sempre ocorre de forma adequada, pois ainda, segundo essa autora, as estratégias de mudança são via de regra "manipulativas" e "controladoras", sem que se considere as variáveis do contexto, no qual interesses e valores podem ser conflitantes, podendo prejudicar os objetivos desse tipo de programa.

Por outro lado, como a "espinha dorsal" do programa é aceitar e trabalhar as diversidades presentes em sala de aula, deve-se levar em consideração que os professores atuantes apresentem também diferenças individuais que podem ter efeito positivo nas dinâmicas adotadas, desde que sejam respeitados os objetivos propostos.

A ideia central desse programa é trabalhar os conceitos de aprendizagem ativa e de inteligências múltiplas, na concepção de Piaget, Dewey e Gardner.

\section{Inteligências múltiplas e as diferenças individuais}

Considerando as inteligências múltiplas, a pesquisa de Howard Gardner sobre o desenvolvimento das capacidades cognitivas humanas gerou uma definição pragmática renovadora do conceito de inteligência, expressando-se da seguinte forma:

* A capacidade para resolver problemas encontrados na vida real;

* A capacidade para gerar novos problemas a serem resolvidos;

* A capacidade para fazer algo ou oferecer um serviço que é valorizado em sua própria cultura.

A definição de Gardner (1995) da inteligência humana ressalta a natureza multicultural da sua teoria. Segundo esse autor, as inteligências são linguagens que, em parte, sofrem a influência da cultura em que a pessoa nasceu. São ferramentas para a aprendizagem, resolução de problemas e criatividade que todos os seres humanos podem usar.

Da perspectiva de Gardner, a essência da Teoria das Inteligências Múltiplas para a educação é respeitar as muitas diferenças entre as pessoas, as múltiplas variações em suas maneiras de aprender e os vários modos pelos quais elas podem ser avaliadas.

Tomando por base a concepção de inteligências múltiplas, é possível pensar uma educação escolar diferente, na qual a visão pluralista da mente distingue muitas facetas diversas da 
cognição, reconhecendo que as pessoas têm forças cognitivas diferenciadas e estilos de aprendizagem contrastantes.

A escola que considere a teoria de Gardner, como é o caso das escolas que adotam o PIE, reconhece que crianças de várias idades ou estágios têm necessidades diferentes, percebem as informações culturais de modo diverso e assimilam noções e conceitos a partir de diferentes estruturas motivacionais e cognitivas, sendo que o tipo de projeto educacional que uma escola assim se propõe deve considerar esses fatores do desenvolvimento.

Em se tratando de fornecer elementos sobre como lidar com as diferenças entre os alunos, a Teoria das Inteligências Múltiplas abre as portas para uma ampla variedade de estratégias de ensino, que muitas vezes são inovadoras (Smole, 2000).

Segundo Armstrong (2001), essa teoria alerta que não existe um conjunto de estratégias de ensino que funcione melhor sempre para todos os alunos. Cada criança tem inclinações diferentes nos oito tipos de inteligência, de modo que qualquer estratégia específica provavelmente será muito bem-sucedida com um grupo de alunos e não tão bem-sucedida com outros. 0 professor que cria estratégias de ensino com base nas inteligências múltiplas faz os alunos interagirem de formas diferentes como, por exemplo, em pares, pequenos grupos ou grupos maiores, e reserva um tempo para a autorreflexão individual. No PIE, esses aspectos são fundamentos para a organização do trabalho escolar.

\section{Aprendizagem ativa gerencia o programa}

Considerando-se a outra ideia central do PIE, a escola ativa propõe a aprendizagem por meio da atividade pessoal do aluno. Transfere o controle do processo de aprendizagem do professor para o estudante, cabendo a este formular e perseguir seus próprios objetivos de aprendizado e selecionar os recursos que melhor se encaixem nas suas necessidades.
A aprendizagem ativa é aquela que é construída pelo educando a partir de sua interação com os conteúdos socioculturais, exigindo também um ensino ativo. 0 educador, ao trabalhar com seus educandos, deverá estar atento para propor conteúdos e atividades que lhes possibilitem aprender pela ação.

A experiência do PIE, introduzida do $1^{\circ}$ ao $5^{\circ}$ ano do ensino fundamental, segue os princípios da aprendizagem ativa que redefine os objetivos da educação, da transmissão dos conteúdos, do papel do professor e da organização da aula. Nessa nova concepção, respeita-se o fato de que as crianças são distintas em seu desenvolvimento físico, psicomotor e cognitivo, ou seja, cada criança é dona de características específicas.

As ideias que constituem as bases dessas modificações se orientam por teorias educativas e psicológicas amplas, como as de Piaget (1988), e teorias socioeducativas, como as de Dewey (1976).

0 pensamento de Dewey consiste em sua tentativa de unir a noção de inteligência individual e social (cooperativa) com o discurso da democracia e liberdade. Segundo esse autor, uma das vantagens de se conseguir essa liberdade é que favorece as condições do processo de aprendizagem. Para que isso transcorra, apesar de constituírem um grupo geral, o professor deve considerar cada aluno individualmente, pois nenhum caso é exatamente igual ao outro. A uniformidade do ensino gera uma imobilidade que acaba por desconsiderar as tendências individuais.

A visão de Dewey da sala de aula como um microcosmo da sociedade é um sistema de instrução baseada em técnicas semelhantes às inteligências múltiplas (Gardner, 1987). Muitos modelos educacionais alternativos atuais são essencialmente sistemas de inteligências múltiplas, aí se inclui a aprendizagem ativa onde está pautado o PIE.

Gardner (1995) descreve como escola ideal aquela que leva em consideração que nem todas as pessoas têm os mesmos interesses e habilidades, ou seja, nem todos aprendem da mesma maneira. Esse modelo de escola também deve ponderar que ninguém pode apren- 
der tudo o que há para ser aprendido, pois atualmente o ideal de se aprender "tudo" não é mais possível. Esse autor ressalta a importância da educação centrada no indivíduo, na qual o objetivo deve ser construir uma educação em torno das potencialidades e inclinações específicas de cada criança.

Considerando-se a ideia central do programa e baseado nesse referencial teórico, o presente estudo destinou-se a analisar o PIE a partir de uma pesquisa de natureza qualitativa na Escola Israelita Brasileira Eliezer Steinbarg Max Nordau, da rede particular do Rio de Janeiro. A partir de entrevistas - realizada com 20 professoras, que atuam do $1^{\circ}$ ao $5^{\circ}$ ano do ensino fundamental, e 4 dirigentes da escola , análise documental e observação participante no período de março a agosto de 2003, podem-se observar os avanços e desafios que um projeto dessa natureza apresenta e chegar a algumas conclusões.

\section{Caracterização da pesquisa}

A partir do referencial teórico, o levantamento de dados e sua posterior análise fundamentaram-se na metodologia qualitativa que, segundo Alves-Mazzoti e Gewandsznajder (2001), caracteriza-se pela ênfase nos sujeitos, privilegiando as percepções destes e pela ênfase no papel da ciência como transformadora da realidade, considerando que os valores do pesquisador estão presentes em todo o processo de investigação, já que análise e interpretação do processo de produção e transformação do conhecimento fazem parte do atual contexto em que vivemos e pesquisamos.

Segundo Lüdke e André (1986), a pesquisa qualitativa caracteriza-se por ter o ambiente natural como fonte direta de dados e o pesquisador como principal instrumento para a coleta destes. Outra característica citada pelos autores é o fato de tal pesquisa preocupar-se com o processo, mais do que com o produto, garantindo a confirmação ou não das hipóteses iniciais do estudo.

\section{O contexto e os sujeitos da pesquisa}

A escola onde foi realizada a pesquisa caracteriza-se por atender à comunidade judaica, tendo em seu currículo disciplinas relacionadas a essa cultura - além das do currículo nacional -, tais como: Hebraico, Tanach, Conhecendo lsrael, entre outras.

Do $1^{\circ}$ ao $5^{\circ}$ ano, a escola funciona em turno integral, das 7:45 às 15:00h, necessidade sentida pela direção após a implantação do programa. Antes do PIE, funcionavam em único turno. Essa mudança ocorreu para que se garantisse um tempo mais extenso e contínuo às disciplinas do núcleo comum e ao ensino judaico, no sentido de tornar o processo de aprendizagem mais prazeroso, leve, menos corrido e de favorecer a prática do trabalho diversificado proposto pelo PIE.

Para a análise desse programa, foram utilizadas três técnicas de coleta de dados: a análise documental, entrevistas e observação participante.

\section{Análise documental}

A análise dos documentos teve como objetivo complementar as outras técnicas de coleta de dados que serão esclarecidas adiante. Os documentos podem ser considerados uma fonte rica e estável para a pesquisa, nos quais podem ser colhidas evidências que fundamentem as observações do pesquisador.

No presente trabalho, foi feita uma pesquisa bibliográfica sobre a origem do PIE em lsrael, em documentos que se encontram no Órgão de Educação Judaica do Rio de Janeiro (Vaad-Hachinuch) e um levantamento bibliográfico a partir do referencial teórico.

\section{Observação}

A observação precisa ser controlada e sistemática para que seja um instrumento válido e fidedigno durante a pesquisa. Possibilita um contato pessoal e estreito do pesquisador com o fenômeno pesquisado (Lüdke; André, 1986). 
Denzin (1978) descreve a observação participante como uma estratégia de campo que combina simultaneamente a análise documental, a entrevista aos atores envolvidos, a participação e a observação direta. Na observação participante, o pesquisador interage diretamente com os sujeitos, tornando-se parte do meio em que o estudo está sendo realizado, participando do cotidiano dos atores evolvidos e tendo maior compreensão das situações vividas pelos sujeitos envolvidos na pesquisa.

Para a análise do PIE, foram realizadas observações das aulas, tendo como alvo as práticas de trabalho do professor e a autonomia dos alunos para cumprir as tarefas. Esse instrumento permite identificar comportamentos não intencionais ou inconscientes e explorar tópicos que os professores não se sentem à vontade para discutir. Também, por meio das observações, pode-se registrar o comportamento dos professores e alunos em seu contexto temporal-espacial.

A princípio, tínhamos a intenção de realizar observações livres, porém percebemos que durante a nossa presença em sala de aula as professoras conversavam conosco com o objetivo de esclarecer o trabalho que estavam desenvolvendo e, ao final da aula, nós também as procurávamos para uma conversa informal. Com isso, passamos a realizar uma observação participante, visando descrever e compreender comportamentos não predeterminados que ocorriam no dia a dia. As observações foram realizadas em turmas do $1^{\circ}$ ao $5^{\circ}$ ano do ensino fundamental no período de março a agosto de 2003.

Antes de começarmos essas observações, todos os objetivos do estudo foram revelados aos professores envolvidos na pesquisa, inclusive os horários em que estaríamos em sala de aula. Em média, foram realizadas quatro observações por turma.

Em cada uma das turmas, do $1^{\circ}$ ao $4^{\circ}$ ano, a observação aconteceu nos tempos de núcleo comum (no qual são abordados assuntos ligados a matemática, português, ciências e estudos sociais) que são ministrados pela mesma professora.

A partir do $5^{\circ}$ ano, as disciplinas citadas são conduzidas por professores específicos para cada uma delas, o que tornou mais longo o trabalho de observação nessa série.

\section{Entrevistas}

As entrevistas realizadas tiveram o objetivo de complementar e possibilitar um novo enfoque sobre as impressões registradas durante a observação participante, além de proporcionar a interação, permitindo a captação imediata e corrente da informação desejada (Lüdke; André, 1986).

Para a validação dos roteiros de entrevista, foi aplicado um pré-teste em outra escola judaica onde o PIE também é adotado, a fim de se avaliar as questões e corrigir as modificações que se mostraram necessárias.

Já com os roteiros revistos, foram realizadas as entrevistas semiestruturadas nas quais o entrevistado respondeu a perguntas específicas, levando-se em consideração os seus termos próprios. Como o foco da pesquisa é fazer uma análise do PIE, foram feitas entrevistas com 20 professoras, 3 coordenadoras e uma diretora que participam do programa a fim de avaliar como a escola medeia este.

Para interpretação desses dados, foram criadas categorias de análise (categorização) baseada em Laurence Bardin (1977). A categorização é uma operação de classificação de elementos constitutivos de um conjunto, por diferenciação e por reagrupamento segundo o gênero, com os critérios previamente definidos. As categorias são classes as quais reúne um grupo de elementos sob um título genérico, agrupamento esse efetuado em razão dos caracteres comuns desses elementos. A categorização comportou duas etapas:

- 0 inventário: isolar os elementos;

- A classificação: repartir os elementos e procurar certa organização para as mensagens. 


\section{Análise geral dos dados e o paradigma indiciário}

Nossa intenção, ao analisarmos todos os instrumentos de pesquisa, era a de procurar indícios de aproximação para as respostas de nossas perguntas, bem como de confirmação ou refutação às nossas hipóteses.

Utilizamos aqui o termo indícios uma vez que consideramos que em uma pesquisa de mestrado nossos dados e reflexões não são suficientes para apontar respostas definitivas para questões tão complexas quanto essas que decidimos investigar.

Nossa interpretação relacionada à leitura de indícios ocorreu a partir dos trabalhos do historiador Carlo Ginzburg (1991), que pressupõe para um avaliador, independentemente de sua área de atuação, a capacidade de não se ater apenas às caracteristicas mais marcantes de um fenômeno ou objeto a ser observado, mas no exame de pormenores, de dados que seriam marginais, menos expressivos para compreendê-lo. Pressupõe um reconhecimento de minúcias, a percepção de uma realidade imperceptível imediatamente, a busca por pistas, que permitam captar informações mais profundas, fazer sua interpretação e diagnóstico.

Para o autor, esse deve ser um paradigma "conjectural" que se relaciona a um método interpretativo, no qual detalhes aparentemente irrelevantes, sem nenhuma importância, são formas de acesso a certa realidade. Esses detalhes podem fornecer o caminho para redes de significados mais profundos, inacessíveis de outro modo.

Ginzburg (1991) afirma que uma atitude de leitura de indícios por parte de um investigador exige uma atitude orientada para a análise de sintomas, de pistas, de indícios que permitam reconstruir a história daquilo que observamos e permitir a análise de casos mais individuais. Para o autor, apenas mediante observação e registro atentos é possível elaborar histórias precisas.

\section{Conclusão}

A análise do Programa de Inovação Educativa, considerando-se o quadro teórico e os dados obtidos na pesquisa de campo, permitiu que as questões dessa pesquisa fossem respondidas, identificando alguns fatores relevantes em relação ao método proposto.

Em relação ao primeiro objetivo, ressaltase que esse programa mostrou que tem como características principais uma inovação no modelo de aprendizagem, centrado no aluno, com a utilização de estratégias diversificadas, que consideram as diferenças individuais e incentivam a participação discente, inclusive na proposta de temas extracurriculares, mas de interesse para a ampla formação e desenvolvimento deles, por meio da socialização das informações.

Segundo os autores estudados, as relações que emergem da sala de aula transformam os sujeitos partícipes do processo, gerando benefícios coletivos, que fazem da educação um dos principais pilares das mudanças sociais de longo alcance.

Os chamados "modelos alternativos de educação”, que se utilizam de métodos e técnicas inovadoras, ao longo de sua evolução, têm encontrado algumas resistências estruturais e conjunturais, muitas vezes sem que seja oferecida a necessária sustentação pedagógica no que se refere aos elementos colocados para essa argumentação contrária. Entende-se que somente por meio do apoio a pesquisas sistemáticas sobre o assunto e com as necessárias adaptações dos métodos propostos poderão ser firmadas novas concepções, favoráveis ou não a esses métodos.

Em relação ao segundo objetivo, ou seja, a identificação das dificuldades dos professores e da escola na aplicação do programa, identificou-se que a escola necessita estar preparada para esse tipo de trabalho, oferecendo algumas condições básicas, tais como uma grade que permita tempos de aula seguidos, material adequado às dinâmicas desenvolvidas e formação específica de profissionais para que o método seja aplicado dentro dos objetivos propostos. Nesse sentido, em relação às dificuldades dos professores e da escola, em relação à implantação do PIE, pode-se observar que há neces- 
sidade de revisão da estrutura de horários, pois o método vem geralmente sendo aplicado somente uma vez por semana em decorrência da impossibilidade de tempos de aula contínuos.

Outra questão que dificulta esse tipo de trabalho é o fato de os professores terem que cumprir um extenso programa curricular, prejudicando o aprofundamento de alguns temas propostos, principalmente aqueles que são inovadores em relação à grade inicial apresentada, havendo no $1^{\circ}$ ano maior possibilidade para esse desenvolvimento, pois o currículo é menos extenso que nas demais séries. As disciplinas Língua Portuguesa e Matemática, por terem carga horária mais extensa, permitem maior adaptação ao programa.

A escola ainda está em processo de adaptação a esse programa inovador e, para isso, tem necessidade de maior investimento em tecnologia, formação de novos docentes e aperfeiçoamento dos que já participam do programa, num processo de educação continuada, destinado ao aperfeiçoamento dos métodos utilizados, para a superação das dificuldades encontradas e para a análise sistêmica dos dados obtidos.

Respondendo ao terceiro objetivo, voltado para as contribuições do programa para a escola, percebeu-se que as professoras que estão participando do programa desde a sua implantação já incorporaram o que chamam de "mutêmico", termo esse oriundo de Oraá Mutemet, nome do programa em hebraico. A partir dessa assimilação, a avaliação docente sobre o programa e sua comparação com os demais métodos de aprendizagem enriquecem o processo e possivelmente, ao longo do tempo, podem permitir a efetiva implantação com os necessários ajustes. A atuação docente, a partir do saber e das representações dos alunos, exercendo a função de orientador, traz novas concepções apoiadas no modelo proposto nesse programa.

Como fator relevante, observou-se que as atividades diversificadas, além de possibilitarem o desenvolvimento da autonomia, facilitam o atendimento às crianças com maior grau de dificuldade de aprendizagem, desenvolvendo a solidariedade e a cooperação entre elas, promovendo a integração e a formação de equipes de trabalho, fortalecendo assim os níveis de socialização e de afetividade, que dão todo o sentido aos temas trabalhados e aos projetos a serem desenvolvidos.

Outro passo que a escola vem adotando é a adaptação do sistema de avaliação ao programa, implantando modelos mais elásticos e maleáveis com a utilização de outros instrumentos além da prova formal. Entre outros, são considerados os níveis de participação e de interesse, porém esses critérios qualitativos são convertidos em nota.

Pelas entrevistas realizadas com as coordenadoras do programa e dados obtidos, percebe-se que esse assunto vem sendo trabalhado e discutido, envolvendo os professores com o objetivo de que sejam definidos critérios para essa conversão.

Evidenciou-se que o trabalho das professoras fora da escola é tão grande ou maior do que o ali desenvolvido, pois exige um preparo específico, mas, mesmo assim, as entrevistas revelaram que esse trabalho tornou-se muito mais prazeroso.

As salas de aula onde o programa é desenvolvido são bem diferentes das demais: os murais são criativos, há livros e jogos ao alcance dos alunos, com exposição de trabalhos já concluídos; há todo um sentido de participação e de humanização. A programação do dia é colocada no quadro, mesmo quando não há previsão de trabalho diversificado. Os alunos movimentam-se durante as aulas para o desenvolvimento dos trabalhos de equipe, interagindo com os demais grupos, podendo buscar informações ou materiais em ambientes da escola, externos à sala de aula como, por exemplo, a biblioteca.

Existe um estímulo para a autonomia dos alunos que é regulada pelo professor de forma aberta e participativa. Percebe-se que o programa tornou-se um desafio para a escola e seus professores, na busca de um modelo pedagógico voltado para a formação de indivíduos mais preparados para interagir na sociedade. Entretan- 
to, cabe ressaltar que essa pesquisa não esgota o assunto, tornando-se necessário um acompanhamento e um aprofundamento da proposta ao longo de um período de sua aplicação para que possam ser consolidados ou mesmo aperfeiçoados alguns dos aspectos aqui identificados.

Foram muitas as aprendizagens propiciadas com a análise do programa: entre elas, a importância da variedade de estratégias didáticas utilizadas para levar o aluno a aprender; a reação da equipe pedagógica e dos alunos a um programa de inovação; como uma inovação pode modificar o dia a dia de uma escola; e a estrutura necessária para propor, desenvolver e ver os resultados de um programa como esse que analisamos.

\section{Referências bibliográficas}

ALVES-MAZZOTI, A. J.; GEWANDSZNAJDER, F. 0 método nas ciências naturais e sociais - pesquisa quantitativa e qualitativa. São Paulo: Pioneira Thomson Learning, 2001.

ARMSTRONG, T. Inteligências múltiplas na sala de aula. Porto Alegre: Artmed, 2001.

BARDIN, L. Análise de conteúdo. Lisboa: Edições 70, 1977.

BRASIL. Lei de Diretrizes e Bases da Educação Nacional: Lei 9394/96. Disponível em <www.planalto.gov.br>. Acesso em: 20/ $10 / 2007$.

DENZIN, N. The research act. New York: McGraw Hill, 1978.

DEWEY, J. Experiência e educação. Tradução de Anísio Teixeira. 2. ed. São Paulo: Nacional, 1976.

FORQUIN, J. C. Sociologia da educação: 10 anos de pesquisa. Rio de Janeiro: Vozes, 1995.

GARDNER, H. Beyond IQ: education and human development. Harvard Educational Review, v. 57, n. 2, p. 187-193, 1987. Inteligências múltiplas: a teoria na prática. Porto Alegre: Artes Médicas, 1995.

GIMENO SACRISTÁN, J. 0 currículo: uma reflexão sobre a prática. Porto Alegre: Artmed, 2000.

GLUBMAN, R.; YRAM, I. Desenvolvimento das técnicas de ensino em Israel. Universidade de Bar-llan, 1996.

GINZBURG, C. Mitos, emblemas e sinais. São Paulo: Cia das Letras, 1991.

HERNÁNDEZ, F. Aprendendo com as inovações nas escolas. Porto Alegre: Artes Médicas Sul, 2000.

LÜDKE, M.; ANDRÉ, M. Pesquisa em educação: abordagens qualitativas. São Paulo: EPU, 1986.

MELLO, G. N. Cidadania e competitividade. São Paulo: Cortez, 1998.

MOULIN, N. Projeto novo saber: mudanças e inovações em educação. São Gonçalo: Universidade Salgado de Oliveira, 1988.

SANTOMÉ, J. T. Globalização e interdisciplinaridade: 0 currículo integrado. Porto Alegre: Artes Médicas, 1998.

SECHTER, F. Desafios da educação em um país nascente. Revista Fundo Comunitário, Rio de Janeiro, ano Il, n. 1, 2001.

SMOLE, K. C. S. Matemática na educação infantil: a teoria das inteligências múltiplas na prática escolar. Porto Alegre: Artmed, 2000. 
THURLER, M. G. Inovar no interior da escola. Porto Alegre: Artmed, 2001.

Recebido em 06.04.09

Aprovado em 15.10 .09

Letícia Portieri Monteiro, mestre em educação pela Universidade Federal do Rio de Janeiro, é mediadora pedagógica do curso de especialização em Tecnologias em Educação/PUC-Rio e supervisora de formação do Programa "Cientistas do Amanhã"/Sangari Brasil. E-mail: leticiaportieri@globo.com.

Kátia Stocco Smole, doutora em educação pela USP, é coordenadora do Mathema, professora orientadora convidada pela UFRJ no programa de mestrado em educação e coordenadora do curso de pós-graduação lato-sensu Fundamentos do Ensino da Matemática na UNIFRAN. 